\section{CERN management faulted over sudden budget crisis}

\section{David Adam, London}

Soaring magnet costs, shaky project management and the lack of any contingency funds are being blamed by researchers for the cash crisis facing the Large Hadron Collider (LHC) currently being built at CERN, the European particle physics laboratory.

CERN says that the project, which is up to SFr850 million (US\$530 million) over its original SFr2.6-billion budget (see Nature 413,$441 ; 2001$ ), has been hit by large bills for equipment and civil engineering.

Officials at the laboratory, which straddles the border between France and Switzerland near Geneva, say they remain confident that the machine will collide its first protons as scheduled in 2006. But the source of the extra cash needed to meet this deadline remains unclear. CERN researchers and governers have asked why the project slipped so far into the red before the alarm was sounded, and there have already been calls for the resigna-

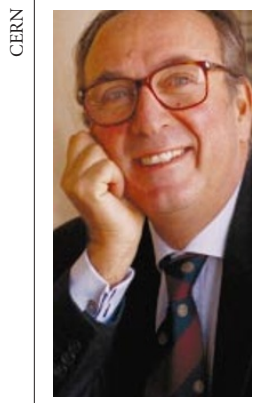

Luciano Maiani faces criticism tion of CERN's director general, Luciano Maiani.

One CERN researcher, who declined to be named, says that poor financial supervision was a factor: "The management should have seen it coming, but financial controls were not done properly and accounting procedures were not careful enough." from CERN staff. thorough cost review was only possible after the closure of CERN's previous big accelerator, the Large Electron-Positron Collider, in November 2000. "Now is the time to act," he says. "A series of measures, including tight monitoring and control of spending, will be presented to our member states in November."

CERN officials plan to set up an 'office for spending control' to oversee its programmes. "This will enable the directorate to react in real time to any problem," says Maiani.

CERN spokesman Neil Calder says that the current financial troubles can be traced back to 1996, when the LHC was approved on a tight budget, with no contingency funds to pay for cost overruns. CERN was "not in a strong negotiating position" at the time, he says, explaining that it had to settle for what was on offer from member states, whoseleaders were nervous about committing funds to a project similar in scope to the US Superconducting Supercollider, which had collapsed amid spiralling costs three years earlier.

Calder says that CERN originally intended to absorb part of any cost overrun by taking

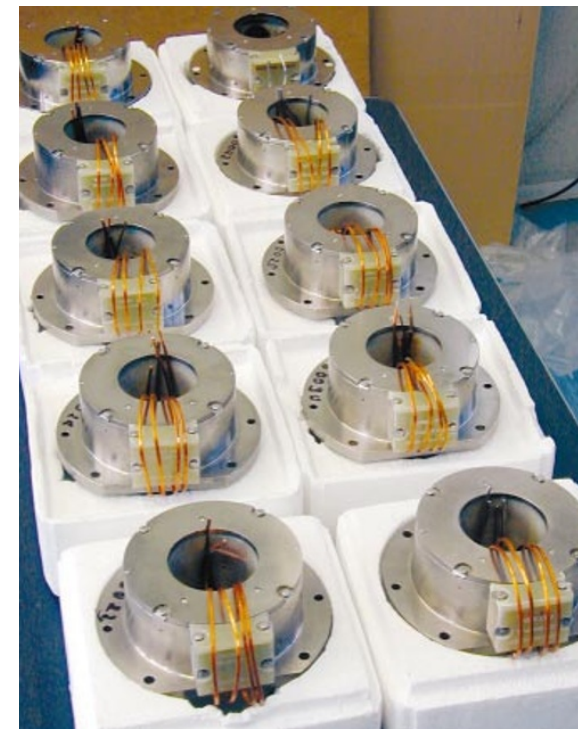

Costly creations: prototype magnets for the Large Hadron Collider were unexpectedly expensive.

longer to build the machine or to pay offloans. "Our contingency was time," he says. But time is running out. Delays in getting the LHC operational will drain researchers and status from CERN. The rival Tevatron facility at Fermilab near Chicago, meanwhile, would enjoy an extended run at tracking down the Higgs boson, an elusive elementary particle that the LHC was largely designed to find.

Hopes that CERN's central operating budget would swallow some overspend have also proved optimistic. SFr 150 million more than expected has already been spent on developing prototype magnets, but none of it has so far been drawn from the central budget. Insiders say that part of the problem in this case was a lack of in-house expertise, which meant that CERN had to pay for private contracts with companies that had little incentive to keep costs down. Quotes for the huge dipole magnets that will steer ions and particles through the LHC accelerator have also been significantly higher than expected.

Representatives from CERN's 20 member states are angry about the revelations especially as CERN's management denied rumours of funding problems in June this year. When the problems were finally discussed by the CERN council on 20 September, delegates from the Netherlands called for Maiani's resignation, according to another delegate. Other council members, all of whom declined to be identified, think that he should stay to help sort out the mess. But they agree that Maiani and other senior CERN managers have some serious questions to answer. "There needs to be a change of climate at CERN," says one delegate.
Ireland weighs up options to buy into European research

Erica Klarreich, London

Ireland, which has boosted its research budgets in a bid to provide greater backing for innovation, is poised to join some of Europe's biggest science collaborations.

A report commissioned from an independent US group recommends that Ireland joins the European Molecular Biology Laboratory (EMBL) as soon as possible and that it then considers joining the European Synchrotron Radiation Facility (ESRF) and the European Southern Observatory (ESO). But it says that joining CERN, the European particle physics laboratory, would be too expensive.

The report was written by specialists in science and technology policy at the Georgia Institute of Technology in Atlanta, for Forfás, an advisory panel funded by the Irish government. It is likely to have a strong influence on the government's decision, expected in the next few months, on which projects to join, although officials say they are also accepting submissions from interested parties.

Ireland plans to spend $\mathbf{4 0 0}$ million euros (US $\$ 368$ million) a year on basic research, more than double its spending in the late 1990s. "In this changed funding environment, we decided it was time to have a serious look at joining some of these organizations," says John Fallon, a senior official in the Department of Enterprise, Trade and Employment, which is responsible for science policy.

The report, published in its final form on 15 September, says that the EMBL's aims fit well with Ireland's research priorities, and notes that membership would be cheapest of the facilities considered, at 450,000 euros per year.

The growing importance of synchrotron research and the public appeal of astronomy led the report's authors to recommend the ESRF and the ESO. In advising against joining CERN, the report cites a lack of Irish high-energy physicists, together with the high membership cost of between 6.5 million and 7.5 million euros per year.

But Irish physicists and some government officials disagree, arguing that membership of CERN would encourage students to enter the field. "It's a chicken-and-egg situation," says Roger O'Connor, director of business and technology in the Department of Public Enterprise. "Particle physics will look much more attractive to researchers looking for doctoral subjects if Ireland becomes a member of CERN." 